\title{
Correction to: Secondary Metabolites from Marine Endophytic Fungi: Emphasis on Recent Advances in Natural Product Research
}

P. V. Bramhachari, S. Anju, Ganugula Mohana Sheela, T. Raja Komaraiah, Peddaboina Venkataiah, and A. M. V. N. Prathyusha

\section{Correction to:}

Chapter 15 in: B. P. Singh (ed.), Advances in Endophytic

Fungal Research, Fungal Biology, https://doi.org/10.1007/978-3-030-03589-1_15

The original version of the book was inadvertently published with incorrect author name "Devanaboyina Venkataiah". The author name has now been corrected to "Peddaboina Venkataiah". 